\title{
Toward Assessment of Information Systems Programs: Evaluating Learning Outcomes in Systems Analysis and Design Courses
}

\author{
A.T. Jarmoszko, O. Petkova and M. Gendron \\ Central Connecticut State University, New Britain, CT USA
}

jarmoszkoa@ccsu.edu petkovao@ccsu.edu gendronm@ccsu.edu

\begin{abstract}
This paper describes a research in progress on the assessment of an undergraduate program in Information Systems. Different assessment methods suitable for MIS program assessment are discussed and a brief description of pilot assessment is provided.
\end{abstract}

Keywords : Program Assessment, Systems Analysis and Design, IS2002

\section{Introduction}

There has been a notable increase of interest in measuring student learning outcomes and in the effectiveness of educational institutions over the last decade. This is at least in part related to the perception that assessment of student learning outcomes should constitute an increasingly important element in academic program reviews and accreditation As various national, regional and campus-level groups debate how to define outcomes for higher education and how to develop the means for achieving these outcomes, the question no longer seems to be whether to assess, but rather how best to perform it.

Yet, within the field of Information Systems, not much has been reported in the literature on program assessment. The focus, rather, has been on the definition of goals and objectives (IS2002) and not on how to measure achie vement and how to develop feedback mechanisms into the process of curriculum design. We believe this shortcoming must be addressed, especially since IS programs have been growing in size and their success needs to be monitored (Pick and Kim, 2000).

This exploratory study describes program assessment initiatives undertaken at the Department of Management Information Systems, School of Business, Central Connecticut State University. During the spring 2002 semester a pilot assessment exercise was conducted within a senior course in the MIS-major core sequence: Structured Systems Analysis and Design (MIS 461).

The presented paper reflects a research in progress. The assessment mechanism is still being refined and a number of options are still being investigated. Another experiment will be conducted during the spring 2003 semester. The intended contribution of the paper is in sharing our work on program assessment with those who are contemplating similar actions within their own institutions.

\section{Background}

Material published as part of these proceedings, either on-line or in print, is copyrighted by Informing Science. Permission to make digital or paper copy of part or all of these works for personal or classroom use is granted without fee provided that the copies are not made or distributed for profit or commercial advantage AND that copies 1) bear this notice in full and 2) give the full citation on the first page. It is permissible to abstract these works so long as credit is given. To copy in all other cases or to republish or to post on a server or to redistribute to lists requires specific permission from the publisher at Publisher@InformingScience.org
Assessment is about setting clear obtainable objectives and measuring progress toward reaching these objectives through comprehensive, systematic, and - and to the highest degree possible objective processes. It is a method for studying what we want students to learn, how much they have learned, and how to design programs to facilitate learning. Assessment can be used to help 
faculty collectively articulate what needs to be taught and why learning matters. It can also serve as an aid in identifying unexpected and unintended program outcomes. Assessment is usually performed at three different levels: classroom, program and general education.

\section{Assessment Methods}

Program assessment should be comprised of multiple indicators, both formative and summative and may use both qualitative and quantitative data. This section of the paper provides a list of possible assessment methods for evaluation learning outcomes, adopted from Rogers (2002), and Prus and Johnson (1994). In addition, the suitability of the methods for assessing MIS programs is discussed.

- Written surveys and questionnaires are very popular methods for assessment. The surveyed individuals are asked to share their perceptions about the issue being assessed via a formally prepared research instrument. Georgia Southern University (Williams \& Price, 2000) and the University of Redlands (Pick \& Kim, 2000) used surveys to assess graduate and undergraduate programs in MIS. Although surveys and questionnaires provide opportunity for a comprehensive assessment, there are some disadvantages associated with them. Logistically, it is difficult to obtain the contact details of former students. Low response rate is another disadvantage.

- A focus group is a guided discussion of a group of people who share certain characteristics related to the research or evaluation question, conducted by a trained moderator. This method can be used in combination with written surveys and questionnaires method, as described by Pick and Kim (2001). Careful consideration should be given to the selection of the group members, not neglecting alumni, advisory boards and other external stakeholders that can contribute greatly to the assessment results.

- Exit and other interviews are often used as assessment method. In them individuals are asked to share their perceptions about the target of being assessed in a face-to-face partially structured research instrument. Segers and Dochy (2001), describe semi-structured interviews for assessment of programs at the Maastricht School of Economics and Business Administration in the Netherlands. Possible involvement of a focus group could be beneficial for the outcome of the assessment. In the cases of large student populations this assessment method can be time consuming and difficult to administer. The design of the research instrument is vitally important and should be approached very seriously.

- Archival Records should be used as a secondary source of data to complement the previous three methods. Biographical, academic, or other file data can be available from college or other age ncies and institutions.

- Commercial, norm referenced, standardized examinations (commercially developed examinations developed by some authoritative institution) are often used in higher education to assess the learning outcomes for a particular region. Standardized tests have known psychometric properties but they are usually not very diagnostic as they probably do not contain questions that address the specific learning objectives outlined by a program (Perrin et all, 2002)

- Locally developed examinations (examinations designed by local staff /faculty) can be used to address specific departmental goals. However, the psychometric properties of these tests must be established to ensure that the tests are accurately measuring what they are designed to measure.

- External examiners can assure the high standards of the program. Experts in the field from outside your program, usually from a similar program at another institution, can be used to conduct, evaluate, or supplement the assessment of your students. 
- Oral examinations (evaluation of student knowledge through a face to face dialogue between the student and the examiner) are suitable for assessing knowledge levels. Time constrains and logistics are usually a hindrance to the use of such method on a wide scale. This method however presents opportunity to the examiner to obtain a better estimation about the knowledge of the student than any other written examination.

- Behavioral observations (measuring the frequency, duration and context of subject's actions, usually in a natural setting with non interactive methods). Although this method is particularly suitable for assessment of programs in Education, Medical Science and the like, it can be used in MIS for assessment of group work. However the group dynamics are not always easier to observe, because most of it takes place out of the class setting.

- Simulations method of assessment is a competency-based measure where a person's abilities are measured in a situation that approximates a "real world" setting. Simulation is primarily used when it is impractical to observe a person performing a task in a real world situation (e.g., on the job). Traditionally simulation has been used in many Business and Information Systems courses. The use of simulation through standardized business cases provides possibility for relatively easy, formalized assessment of the learning outcomes.

- Performance appraisal is the systematic measurement of overt demonstration of acquired skills, generally through direct observation in a "real world" situation e.g., while a student is working as an intern or on a project for client. Most of the activities in any MIS course involve problem solving, decision-making and teamwork. This makes the performance appraisal method one of the most suitable assessment methods.

- Portfolios are collections of work samples, usually compiled over time and rated using rubrics. Portfolios are a vehicle for promoting student and teacher reflection, self-evaluation, and goal setting (Serafini, 2001). The authors of this paper consider portfolios to be very important assessment method in the MIS programs. More discussion on portfolios is provided later in the paper.

A variety of assessment methods were briefly discussed above and an attempt was made to elicit the suitable methods for assessing MIS programs. However such an approach of selecting one assessment method and using it to assess a course or a program can lead to incomplete, incorrect and unfair results. "Assessment that is fair, leading to valid inferences with a minimum of error, is a series of measures that show student understanding through multiple methods. A complete picture of what students understand and can do is put together in pieces comprised by different approaches to assessment" (Rudner and Schafer, 2002).

\section{Pilot Study}

In the Spring 2002 semester, the Department of Management Information Systems at Central Connecticut State University decided to conduct a pilot exercise in assessing its undergraduate program. These actions were mandated by the State of Connecticut legislature. In the Fall 2001, the Department participated in campus-wide series of meetings meant to reaffirm its mission and goals as well as to consider viable program assessment options. After much deliberation on what is possible within the available timeframe it was decided to conduct a course-embedded assessment pilot via the final course in the MIS-major core sequence: Structured Systems Analysis and Design (MIS 461).

\section{Choice of Assessment Method}

We discussed the possible methods of assessment within the SA\&D setting and decided to employ a combination of simulation and performance appraisal through a set of standardized business cases used 
in semester-long group projects. For this purpose a set of three business cases were synthesized from available sources. As part of the required work for MIS 461, groups of students were assigned a business case in which a specific business information need was delineated. Students were then asked to apply the techniques of Systems Analysis and Design, as taught in the course, to solve the case, to document the process of arriving at a solution and to present their design to the class at the end of the semester. Data for the assessment was collected from project deliverables - submitted to the course instructor during the semester - and from project presentations performed at the end of the semester.

\section{Definition of Goals, Learning-outcomes and Performance Criteria}

- Assessment is a method for studying how much students learned what we want them to learn and what the program is designed to help them learn (Perrin at all, 2002). Therefore, programs must first articulate goals and objectives for students. These goals become the foundation of assessment. The following three fundamental objectives were identified: Identify and Analyze Business Information Problems

- Generate and Evaluate Viable Solutions to Bus iness Information Problems

- Design and Implement Chosen Solutions to Business Information Problems

These objectives were used to define student learning-outcomes for the SA\&D pilot and performance metric as follows:

1) Analyze a business need for information (problem), develop an appropriate strategy to solve the problem and provide the required information service.

a. ability to comprehensively describe the business information environment as stated in the case;

b. ability to identify the business information problem as stated in the case;

c. ability to choose the desired solution.

2) Construct and interpret a variety of system description documents, including physical and logical data flow diagrams, entity-relationship diagrams, structure charts, as well as screen, form, and report layouts.

a. ability to construct physical and logical data flow diagrams for the chosen solution;

b. ability to construct entity relationship diagrams for the chosen solution;

c. ability to construct structure charts for the chosen solution;

d. ability to construct screen, form and report layouts for the chosen solution.

3) Communicate effectively, in both written and oral forms, systems specifications, and to be persuasive in these presentations.

a. ability to create persuasive content with sufficient coverage, accuracy and appropriateness to audience;

b. ability to convincingly deliver the created content with proper organization, enthusiasm and clarity;

c. ability to exhibit professionalism in appearance, presentation time management, presentation structure (introduction, body and conclusions), as well as role-playing;

d. ability to use effectively visual aids and supplements;

e. ability to handle audience interaction (e.g. questions and answers). 


\section{Data Collection and Performance Metric}

The above performance criteria were measured on a five-point Lickert scale with 1 indicating a low performance, 3 indicating acceptable performance and 5 indicating high performance.

Assessment was done in two sections of the MIS 461 course. In total, the work of 49 students - or twelve 3-5 member groups - was evaluated. A committee of MIS faculty assessed the work presented using the twelve performance criteria delineated above. Performance was judged both at group and ind $\mathrm{i}-$ vidual level. The input of at least two professors for each criterion was averaged to come up with the final score. Although all groups achieved the minimum acceptable level of at least 3.0, at an individual level the performance of two (out of 49) students was judged to be below the acceptable standard.

The exercise also provided more-specific topic-related feedback. For example, entity-relationship modeling, screen and report design, and use of visual aids in oral presentations were the areas, in which the students achieved the highest results. We believe this is a direct outcome of our Program's curriculum emphasis. Conversely, the topics of data flow modeling and identification of the business information problem were assessed least positively leading to the conclusion that they should receive more attention.

\section{Possible Evolution of Assessment Exercises}

We have conducted the assessment pilot, described above, with an understanding that additional investigation will have to be completed before we settle on the chosen assessment method. Internal discussion on the merits and demerits of course-embedded program assessment has led us to the conclusion that other assessment methods must be explored. The principal shortcoming of course-embedded program assessment, using simulation and performance appraisal lies in the fragmentary set of evaluation data. One course - in this case SA\&D - does not provide enough evidence to assess holistically the entire MIS Program.

\section{Portfolio Assessment}

Possible solution to the above problem is to explore the potential of portfolio assessment. MIS courses provide many opportunities for creating achievement artifacts: programming output, project write-ups, research papers, which could serve as input into students' portfolios. This approach has a number of pros and cons. Since they are put together over time, portfolios can potentially represent a much more comprehensive and holistic set of data on student performance than any other method. They give students the opportunity to utilize course work in portraying learning to a variety of external bodies, including future employers. Furthermore, they promote continuous learning and improvement by giving students the opportunity to revise work already completed.

The principal negative aspect of portfolio assessment pertains to potential pitfalls of inadequate planning. Portfolios are useful assessment tools only if proper mechanisms on portfolio building and evaluation are established. What objectives and audience are portfolios attempting to reach? What can and cannot not be included in students' portfolio? Who determines the final shape of a portfolio: students or faculty? These and other questions must be answered before a program portfolio assessment can be launched.

\section{Planned Assessment Exercises}

\section{Effectiveness of the CASE Tool}

In the Spring 2003 semester, we are planning to use an Oracle CASE (Computer-Aided Software Engineering) tool to teach concepts of Systems Analysis and Design (MIS 461). Although in the past different instructors have used different software tools to facilitate absorption of systems concepts, the Oracle tool (Designer) makes available a greater set of design tools and introduces a new dimension of de- 
sign/implementation integration. For example, students using Oracle Designer are able to generate databases directly from the input of design tools.

A questionnaire addressing a variety of learning outcomes pertaining to the field of systems analysis and design will be designed in order to assess the impact of the CASE tool. The questionnaire will be administered to MIS 461 students in the Spring 2003 (taught with Designer CASE tool) and to students who have taken MIS 461 within the last year (taught without Designer CASE tool). The results of the survey should give us meaningful insights into the use of Oracle Designer CASE tool in a Systems Analysis and Design course and should enhance our understanding of the assessment process.

For students, the use of the CASE tool will make it possible to construct more effective components of their future assessment portfolios and will provide them with additional skills needed in the IT industry.

\section{Concluding Remarks}

This paper presented some of the initial work done on MIS Program assessment at Central Connecticut State University. Different assessment methods suitable for MIS program assessment were discussed, a brief description of pilot assessment was provided and some considerations on future assessment efforts were presented as well.

\section{References}

Davis, G. B., Gorgone, J. T., Couger, J. D., Feinstein, D. L., \& Jr., H. E. L. (1997). IS'97 Model curriculum and guidelines for undergraduate degree programs in information systems. Data Base, 28(1), Bi-B94.

Gorgone, J. T., Davis, G. B., Valacich, J. S., Heikki, T., Feinstein, D. L., \& Longenecker, H. E. (2002). IS'2002 model curriculum guidelines for undergraduate degree programs in information systems. ACM, AIS, AITP. Retrieved 2002, Dec 12 from http://www.is2000.org

Perrin, N., Dillon, T., Kinnick, M., \& Miller- Jones, D. (n.d.). Program assessment, Where do we start? Retrieved 2002, Dec 06 from: http://www.class.pdx.edu/assessment/program assessment.html/

Pick, J.B., Kim J. (2000). Program assessment in an undergraduate information systems program: Prospects for curricular and programmatic enhancement. Proceedings of the $15^{\text {th }}$ Annual Conference of the IAIM, Brisbane, Australia, 2000.

Prus, J. and Johnson, R. (1994). Assessment \& testing myths and realities. New Directions for Community Colleges, No. 88, Winter 94.

Rogers, G.M. (2002). Assessment planning: How much is enough? Presentation made to CCSU faculty, June $21,2002$.

Rudner, L. \& Schaffer, W. (2002). What teachers need to know about assessment. National Educational Association, Washington, DC.

Segers, M. \& Dochy, F. (2001). New assessment forms in problem- based learning: the value- added of the students' perspective. Studies in Higher Education, Volume 26, No.3.

Serafini, F. (2000-2001). Three paradigms of assessment: Measurement, procedure, and inquiry. The Reading Teacher, Volume 54, December 2000/ January 2001.

Williams, S.R. \& Price, B.A. (2000). Strengths and weaknesses of an information system program: A longitudinal assessment of student perceptions. Proceedings of the $15^{\text {th }}$ Annual Conference of the IAIM, Brisbane, Australia.

\section{Biographies}

Andrzej Tomasz Jarmoszko is an Associate Professor in the Department of Management Information Systems, School of Business, Central Connecticut State University. His primary teaching areas are systems analysis and design and data communications and networking. Prior to joining CCSU faculty, Dr. Jarmoszko was Manager for Strategic Planning at a major mobile communications company in Central Europe. His research interests include Information Systems curriculum, aligning knowledge management with the strategy process, and strategic management in the communications industry. 
Olga Petkova is an Associate Professor in the Department of Management Information Systems, School of Business, Central Connecticut State University. She has 25 years of experience, of which 10 years in software development and 15 years in teaching. Prior to CCSU she has been teaching at the University of Natal, University of Durban-Westville, Durban Institute of Technology in South Africa and University of Zimbabwe. Her primary teaching interests are E-Commerce and Systems Analysis and Design. Her research interests are in the area of Software Development Productivity, Community Informatics and Active Learning and Teaching.

Michael Gendron is currently Associate Professor in the Department of Management Information Systems, School of Business, Central Connecticut State University. His research and teaching interests include Networking and Data Communications, Data and Information Quality, Internet Governance and Healthcare Informatics. Prior to joining CCSU faculty, Dr. Gendron has held positions such as Chief Information Officer, Technology Coordinator, Networking and Telecommunications Consultant. He has over 27 years of industry and academic experience. 